Narsey Sugata (Orcid ID: 0000-0002-2039-5025)

Brown Josephine, R. (Orcid ID: 0000-0002-1100-7457)

Colman Robert, A. (Orcid ID: 0000-0002-6046-3176)

Delage Francois (Orcid ID: 0000-0001-8360-8246)

Power Scott, Brendan (Orcid ID: 0000-0002-9596-4368)

Zhang Huqiang (Orcid ID: 0000-0001-5669-1558)

\title{
Climate change projections for the Australian monsoon from CMIP6 models
}

\author{
S. Y. Narsey ${ }^{1}$, J.R. Brown ${ }^{2}$, R. Colman ${ }^{1}$, F. Delage ${ }^{1}$, S. Power ${ }^{1}$, A. Moise ${ }^{3}$, and H. Zhang ${ }^{1}$ \\ ${ }^{1}$ Australian Bureau of Meteorology \\ ${ }^{2}$ School of Earth Sciences, University of Melbourne \\ ${ }^{3}$ Centre for Climate Research Singapore \\ Corresponding author: Sugata Narsey (sugata.narsey@bom.gov.au)
}

\section{Key Points:}

- Australian monsoon changes are smaller in the available CMIP6 ensemble than the CMIP5 ensemble

- CMIP6 models still disagree on changes to Australian monsoon precipitation in a warmer world

- Australian monsoon changes are congruent with the zonal mean precipitation change, more evident in CMIP6 than CMIP5

This is the author manuscript accepted for publication and has undergone full peer review but has not been through the copyediting, typesetting, pagination and proofreading process, which may lead to differences between this version and the Version of Record. Please cite this article as doi: 10.1029/2019GL086816

This article is protected by copyright. All rights reserved. 


\begin{abstract}
Climate change projections for the Australian monsoon have been highly uncertain in previous generations of coupled climate models. The new Coupled Model Intercomparison Project Phase 6 (CMIP6) ensemble provides an opportunity to address the uncertainty in future projections for northern Australia. We find that the range in Australian monsoon projections from the available CMIP6 ensemble is substantially reduced compared to CMIP5, although models continue to disagree on the magnitude and direction of change. While previous CMIP5 studies identified warming in the western equatorial Pacific as important for Australian monsoon projections, here we show that the western Pacific is not strongly connected to northern Australian precipitation changes in the CMIP6 models. By comparing groups of models based on their future projections, we note that the model-to-model differences in Australian monsoon projections are congruent with the zonally averaged precipitation response in the Southern Hemisphere tropics within each model.
\end{abstract}

\title{
1 Introduction
}

Climate change projections for northern Australian precipitation are highly uncertain, with no clear indication of even the direction of change in a future warmer world (Brown et al., 2016; CSIRO and Bureau of Meteorology, 2015). Most of the precipitation over the north of Australia occurs as part of the Australian summer monsoon, the southernmost part of the AsianAustralian monsoon system (Wheeler and McBride 2011; Zhang and Moise 2016). Decreasing the uncertainty in the projections of the Australian monsoon will have far-reaching implications for planning for the future in the region.

While there is some evidence that globally, monsoon regions are likely to become wetter in a warmer world, there is significant uncertainty for regional monsoons (e.g. Turner and Annamalai, 2012; Wang et al. 2012; Christensen et al. 2013; Hsu et al. 2013; Kitoh et al. 2013; Lee and Wang 2014). The Australian monsoon, located in the southern hemisphere, is one such area where the future changes are unclear (Brown et al. 2016; Moise et al. 2012; Zhang and Moise 2016). This may be partly due to hemispheric differences in the future changes, or due to specific aspects of the Australian monsoon, for example, dynamics of the Australian monsoon (e.g. Berry and Reeder, 2016; Narsey et al, 2017; Narsey et al, 2018), or teleconnections with particular weather and climate drivers (e.g. Risbey et al, 2009). Reflecting this uncertainty, models within the Coupled Model Inter-comparison Project (CMIP) Phases 3 and 5 exhibited significant disagreement on not just the magnitude, but also the direction of precipitation changes under a high emissions scenario by late 21st century (Colman et al, 2011; Moise et al. 2012).

Between CMIP3 and CMIP5 there were incremental improvements in the ability of climate models to represent the fundamental features of the monsoon in the historical climate. Improvements in mean-state biases and important regional climate features such as the El Nino Southern Oscillation (ENSO) (e.g. Jourdain et al, 2013; Bellenger et al, 2014) suggested that at least the important drivers of variability of the Australian monsoon may be improved. 
Unfortunately, the range of projected changes in northern Australian precipitation was not significantly reduced.

How then can we understand the reasons for these diverging projections between models? Brown et al (2016 - hereafter BR16) took the approach of comparing subgroups of CMIP5 models, selected based on the Australian monsoon precipitation change they project by the late 21st century under a high emissions scenario. Their key finding was that the models projecting a strong decrease in northern Australian precipitation also projected a strong increase in precipitation over the western equatorial Pacific. Furthermore, those same models were more likely to have larger cold biases in the western equatorial Pacific, a region particularly susceptible to the well-documented equatorial "cold tongue bias" (e.g. Li and Xie, 2014).

The most recent state-of-the-art climate model experiments are now becoming available as part of the CMIP6 ensemble, and promise a wide range of changes and improvements from the CMIP5 ensemble. Here we investigate two critical questions regarding climate model simulations of the Australian monsoon. Firstly, has the range in climate change projections of northern Australian precipitation been reduced in the newer models? Secondly, is the CMIP6 range in climate change projections of northern Australian precipitation related to the same mechanisms inferred by BR16?

\section{Data and Methods}

Monthly precipitation and surface temperature data are used in the present study, for 37 models from the CMIP5 archive (Taylor et al. 2012) and 23 models from the CMIP6 archive (Eyring et al. 2016), listed in Figure 1. For all analysis here we use only the first realization for each model, for both the historical experiments and future high emissions experiments (RCP8.5 for CMIP5 models and SSP5-8.5 for CMIP6 models).

All data are regridded to a common regular 1.5-degree grid using second-order conservative remapping. We define the Australian monsoon region as the land pixels (greater than $30 \%$ land) between $20^{\circ} \mathrm{S}-10^{\circ} \mathrm{S}$, and $120^{\circ} \mathrm{E}-150^{\circ} \mathrm{E}$. To compute the change to Australian monsoon precipitation we compare December to February (DJF) precipitation averaged over the monsoon region for a future period (2050 to 2099) and a historical period (1950 to 1999).

As each model may have a different mean state, the changes in precipitation are presented here as a percentage change compared to the model's historical mean. Furthermore, climate models exhibit a wide range in climate sensitivity, an issue which has become increasingly apparent with several CMIP6 models displaying larger climate sensitivities than the previous model generation (NCC Editorial 2019). Since the true climate sensitivity is not known, we choose to present all change quantities in this study per degree change in global average surface temperature.

Following BR16, we subset and composite CMIP5 and CMIP6 models into three categories - those that become wetter by the late 21st century (WET), drier by the late 21st 
century (DRY), and the remainder which exhibit smaller changes. We limit the DRY and WET categories to eight models each, dividing the available CMIP6 ensemble into approximately equal thirds. To create a fair comparison with the CMIP6 DRY and WET composites, we also limit our DRY and WET groups for CMIP5 to eight models each, selecting the models with the most extreme changes.

Historical simulations are compared against the Global Precipitation Climatology (GPCP) dataset (Adler et al, 2003) and the CPC Merged Analysis of Precipitation (CMAP) dataset (Xie et al, 1997) observation-based datasets for reference, although we note here that the observations span a much shorter range, beginning only in the satellite era (1979-2005). We choose to use longer periods for the model analysis to decrease the influence of decadal variability (e.g. Power et al, 1999).

\section{Results}
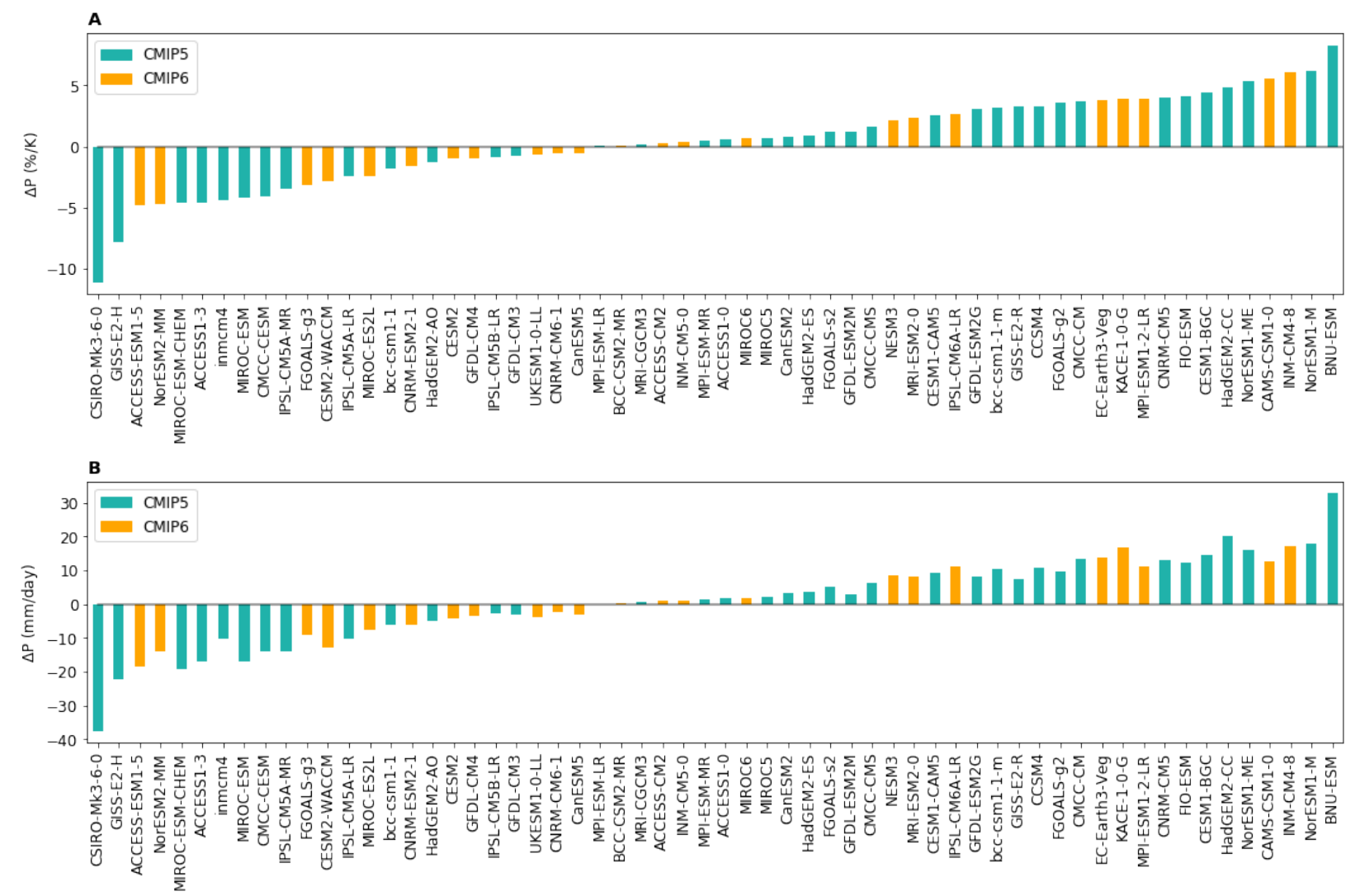

Figure 1: December to February precipitation change averaged over northern Australian land 
for CMIP5 models (green) and CMIP6 models (orange), shown as a percent change per degree change in global average surface temperature (top row), and without any scaling (bottom row). Changes are calculated between the periods 2050-2099 (CMIP6 SSP5-8.5 and CMIP5 RCP8.5 scenarios) and 1950-1999 (historical scenario).

Figure 1a shows the percentage change in DJF precipitation over northern Australia by the late 21st century under the high emissions scenario, scaled by global average temperature change for each model. Using precipitation change not scaled by global warming, or 1950-2099 precipitation trends, does not change the key results presented in this study (not shown). The range in projections is so far reduced, with the largest decline in the CMIP6 models approximately half that from the most extreme CMIP5 model. Disappointingly, the direction of change is still unclear with nearly equal numbers of models projecting increases and decreases in precipitation. In both the CMIP5 and CMIP6 ensemble it appears that the projected changes are not distinctly increasing or decreasing (i.e. not bimodal), but rather the model range forms a continuum from large decreases to large increases. To better understand such inter-model differences, we next investigate how the range in projected changes to the Australian monsoon relate to the large-scale precipitation distribution, before considering the differences between the two extrema of the projected changes. 

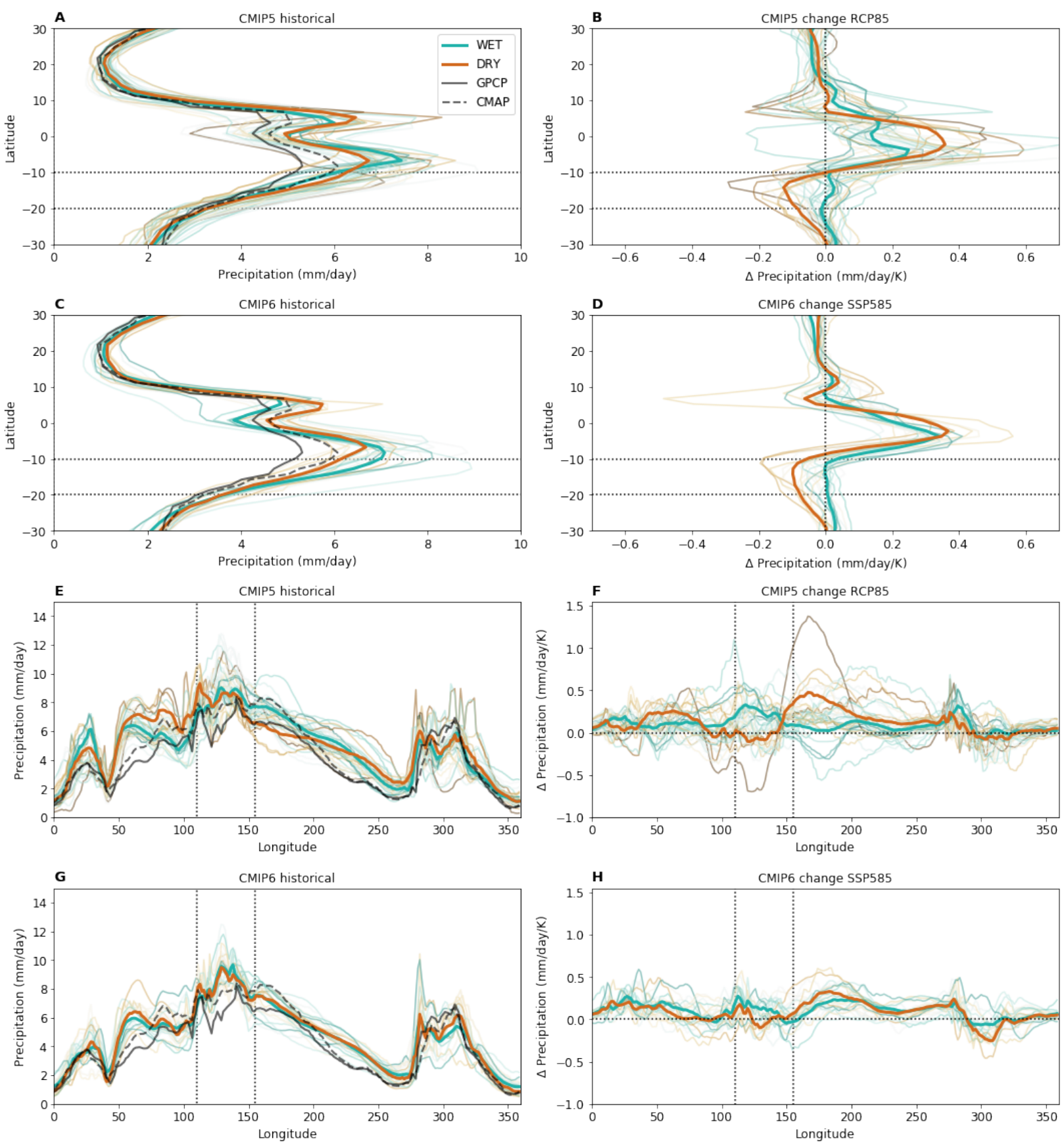

Figure 2: Global zonally averaged historical DJF precipitation (A,C) and future precipitation change (B,D), and meridionally averaged $\left(15^{\circ} \mathrm{S}-15^{\circ} \mathrm{N}\right)$ historical DJF precipitation $(\mathrm{E}, \mathrm{G})$ and future precipitation change (F,H). Northern Australian longitudes/latitudes are indicated with 
black dotted lines, while zero change is indicated with black dotted lines in the right column. Profiles for individual models (thin lines) are coloured according to their Australian monsoon precipitation change, with brown hues representing drying and green hues representing wetting over northern Australia. The thick brown and green lines are the composites for the DRY and WET sub-groups respectively. Precipitation is shown here in $\mathrm{mm} /$ day, and precipitation change is shown per degree change in global average surface temperature for each model. Observed climatologies for GPCP (thick black line) and CMAP (thick dotted black line) are shown for reference (left column).

The global zonally averaged DJF precipitation for CMIP5 and CMIP6 models during the historical period is shown in Figure 2a,c. For both ensembles there is a large spread between models at all latitudes, although the range is largest in the deep tropics. The secondary peak in precipitation in the near-equatorial northern hemisphere is excessive in many CMIP5 models, resulting in nearly symmetrical precipitation peaks on either side of the equator during the Austral summer. While there is no clear distinction between the DRY and WET models historical zonal mean climatology in either CMIP5 or CMIP6, one interesting improvement is the increased interhemispheric asymmetry in CMIP6 models, which is slightly more evident in the WET group. This may reflect a reduction in the double ITCZ bias (Li and Xie, 2014), although this is not investigated further here. Otherwise, it is unclear which group of models is more realistic when compared to observations for both ensembles.

We now consider the change in zonally averaged DJF precipitation (Figure 2b,d) by the late 21st century. For both CMIP5 and CMIP6, the change in the global zonal average precipitation in the southern hemisphere tropics (between $10^{\circ}-30^{\circ} \mathrm{S}$ ) appears to be consistent with the changes over northern Australia. A striking feature in both ensembles is the larger degree of off-equatorial drying in the DRY models, while simultaneously predicting a larger increase in precipitation at the equator. In contrast, on average the WET models experience little off-equatorial drying, if at all, and a more muted increase in precipitation near the equator. This is notable since it indicates a fundamental difference in ITCZ response to global warming between the two sub-groups of models.

The meridional mean of the climatological tropical precipitation $\left(15^{\circ} \mathrm{S}-15^{\circ} \mathrm{N}\right)$ is shown in Figure 2e,g. As with the zonal mean, it is not clear that either sub-group of models (WET/DRY) more accurately reproduces the observed meridional mean tropical precipitation for CMIP5 or CMIP6. The projected changes in the CMIP5 ensemble exhibit much larger diversity compared to the CMIP6 ensemble (Figure 2f,h). In particular, the CMIP5 DRY and WET composites differ strongly over the Maritime Continent to the north of Australia, and over the equatorial Pacific. In contrast, the zonal distribution of projected precipitation change from the CMIP6 ensemble is remarkably consistent, with a much smaller projected range than that from the CMIP5 ensemble, and little discernible difference between the DRY and WET groups. 

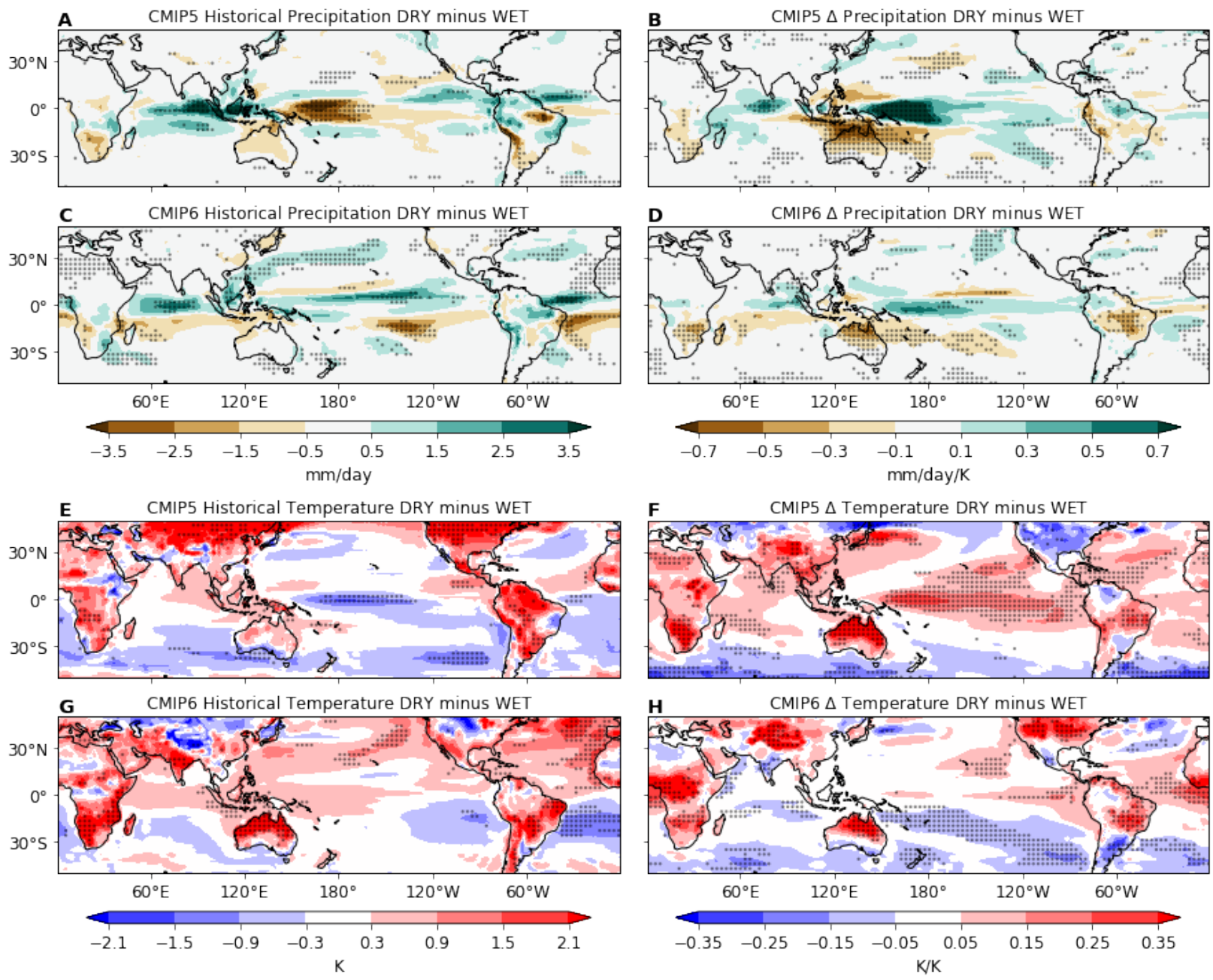

Figure 3: Historical DJF precipitation (A,C) and surface temperature (E,G) climatology and projected changes (right column) for the composite of the DRY group of models minus the composite of the WET group of models for CMIP5 (A,B,E,F) and CMIP6 (C,D,G,H). Precipitation is shown here in $\mathrm{mm}$ /day, surface temperature in Kelvin, and changes are shown per degree change in global average surface temperature for each model. Stipples indicate where at least seven out of eight models in the DRY subset agree on the direction of the anomaly after subtracting the WET subset's multi-model mean, or vice-versa.

We now compare the composites for the DRY and WET groups of models for both CMIP5 and CMIP6, to investigate the spatial coherence of any differences between the groups. The difference between DRY and WET historical DJF precipitation climatologies is shown in 
Figure 3a,c. As highlighted by BR16, a distinct difference between the CMIP5 DRY and WET groups is seen in the western equatorial Pacific, with the DRY models having lower precipitation in that region during the historical period (Figure 3a). In comparison the CMIP6 DRY and WET groups are relatively similar over the western equatorial Pacific, however they exhibit a clear difference in the intertropical convergence zone (ITCZ), with higher precipitation near the equator and less precipitation in the southern hemisphere off-equatorial latitudes for the DRY models historical climate composite compared to the WET models.

Comparing the projected changes (Figure 3b,d), a strong pattern emerges for the difference between DRY and WET CMIP5 groups, consistent with the results of BR16. While a large region encompassing the north of Australia experiences much stronger drying, the western equatorial Pacific experiences much stronger wetting in the DRY group compared to the WET group in CMIP5. A similar, but much more muted pattern emerges for the precipitation change composite of CMIP6 DRY minus WET groups, noting here that the largest difference does still occur in the western equatorial Pacific. In part this will reflect the absence of very large 'outliers' in the CMIP6 projections for northern Australia. One interesting feature seen in both the CMIP5 and CMIP6 ensemble is the difference in projected near-equatorial drying for the southern hemisphere continental land masses in the DRY minus WET composites. This pattern appears to be stronger over southern Africa and northern Australia than it is for the South American region. Nevertheless, it appears that the grouping of DRY and WET models using northern Australian precipitation changes has some relationship to other southern hemisphere continental regions.

What lies behind the large precipitation pattern differences in DRY and WET models in the two ensembles? Figure 3e-h shows blended sea and air surface temperature differences between the DRY and WET models. As noted by BR16, CMIP5 models that project drying over northern Australia tend to experience larger warming in the western equatorial Pacific, and in the current climate tend to be cooler on average in that region, an area susceptible to the welldocumented 'cold-tongue' bias ( $\mathrm{Li}$ and Xie, 2014). By contrast, for the available CMIP6 ensemble, WET/DRY model differences are not marked in the western equatorial Pacific. Instead, a spatially coherent pattern is evident in the interhemispheric difference in historical climatological sea surface temperature (SST). We find that on average, the CMIP6 DRY models are warmer over the northern hemisphere oceans than the WET models during the historical period. This pattern is consistent with the precipitation composites, which showed DRY models having a more northward-located ITCZ than the WET models on average.

The CMIP6 DRY models warm less on average over the southern hemisphere oceans than the WET models. Perhaps related to this, is the coherent difference in temperature over southern hemisphere land. Given that precipitation and temperature are strongly related over tropical land regions (e.g. Hurley and Boos, 2013) it is perhaps not surprising that the offequatorial land-regions are warmer in the future in the DRY models than the WET models. We note that a similar pattern is observed for the CMIP5 ensemble. 

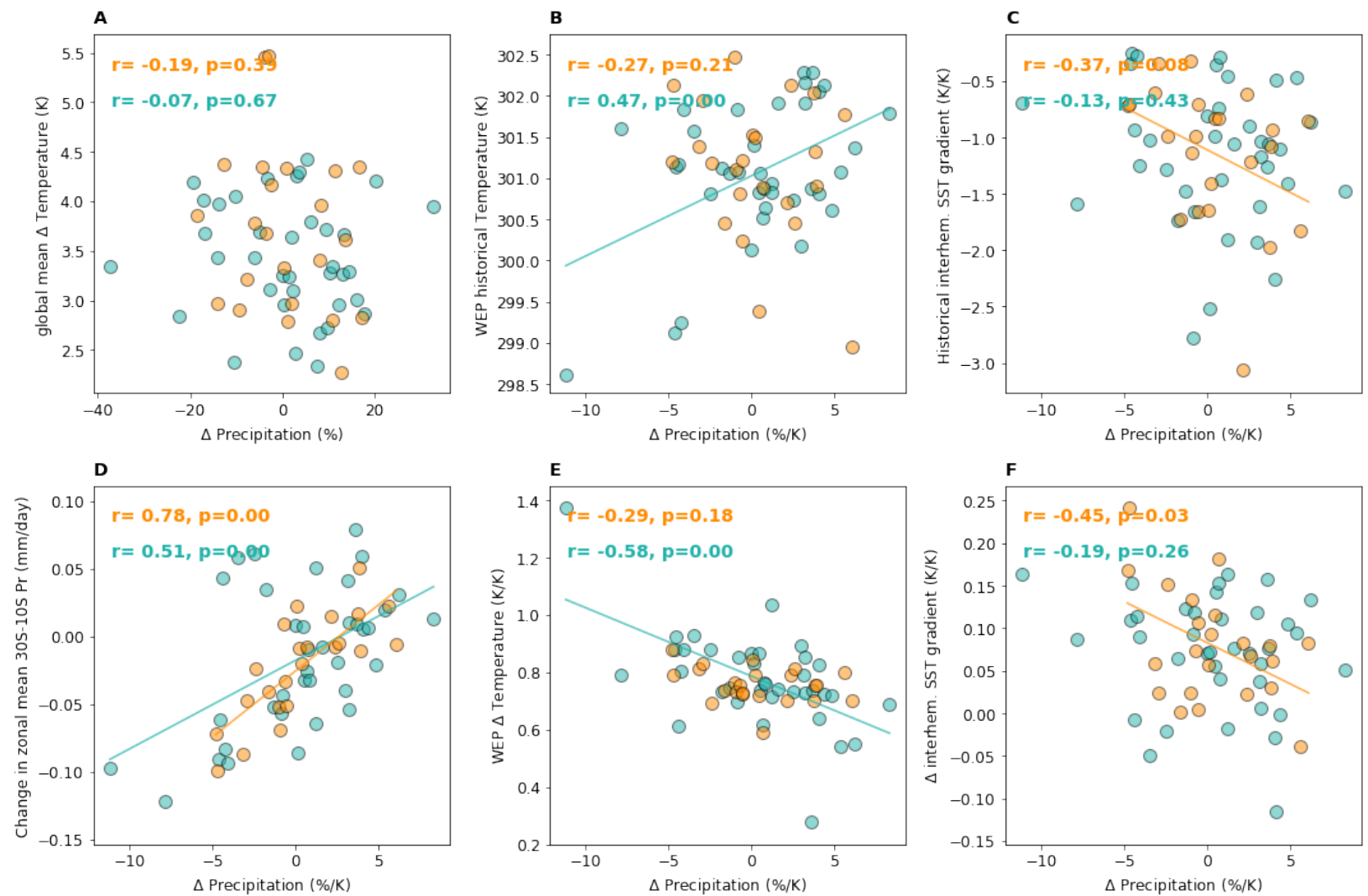

Figure 4: Scatter plots showing the relationship between Australian monsoon precipitation percent change by late 21st century against global averaged surface temperature change (A), western equatorial Pacific historical SST (B), interhemispheric historical SST gradient (40S40N) (C), change in zonal mean precipitation averaged between 30S-10S (D), change in western equatorial Pacific SST (E), and change in interhemispheric SST gradient by late 21st century (F). All precipitation changes are plotted as a percent change per degree global warming, except for (A). A line of best fit is plotted where the correlation is considered significant (p-value less than 0.1). CMIP5 models are indicated with green circles while CMIP6 models are shown in orange.

The analysis described above suggest some features relating changes in the Australian monsoon to either large-scale changes (global or hemispheric), or specific teleconnections (e.g. with the Walker circulation, via western equatorial Pacific SST). In Figure 4 we investigate how well the changes in Australian monsoon precipitation correlate with some of those features. Firstly, we note that neither the rate or direction of change in Australian monsoon precipitation scales with global surface temperature change in either the CMIP5 or CMIP6 ensembles (Figure 4a). As highlighted by BR16, the change in Australian monsoon precipitation in CMIP5 models 
is significantly correlated with both the historical SST ( $\mathrm{r}=0.47)$ and future SST changes $(\mathrm{r}=-0.58)$ in the western equatorial Pacific (Figure 4b,e). However, no such statistically significant relationship is found for the available CMIP6 ensemble. In particular, the range in projected SST changes in that region is reduced in CMIP6 compared to CMIP5 (Figure 4e). The difference in DRY and WET group SST composites in Figure 3 suggested that spatially coherent historical climatology interhemispheric SST differences may be related to Australian monsoon precipitation changes for CMIP6 models. Further inspection of this shows that the historical (Figure 4c) and future changes (Figure 4f) to the interhemispheric SST gradient are both correlated with Australian monsoon precipitation changes in the CMIP6 ensemble, but not in the CMIP5 ensemble. Figures 2 and 4 suggest that the drying or wetting of the Australian monsoon may be related to a zonally symmetric difference between DRY and WET models in both CMIP5 and CMIP6. In Figure 4d we find that the change in Australian monsoon precipitation is significantly correlated with the zonal mean change in precipitation averaged between $30^{\circ} \mathrm{S}$ and $10^{\circ} \mathrm{S}$ for both the CMIP5 ( $\left.\mathrm{r}=0.51\right)$ and CMIP6 $(\mathrm{r}=0.78)$ ensemble. These relationships are significant even with the removal of the Australian monsoon region from the zonal mean (see supplementary Figure 5), albeit slightly weaker ( $\mathrm{r}=0.30$ for CMIP5 and $\mathrm{r}=0.63$ for CMIP6). Similarly, the change in Australian monsoon precipitation is significantly correlated with the other land region changes between $30^{\circ} \mathrm{S}$ and $10^{\circ} \mathrm{S}$ excluding northern Australia $(\mathrm{r}=0.39$ for CMIP5 and r=0.55 for CMIP6).

\section{Discussion and Conclusions}

We have investigated the long-term climate change projections of Australian monsoon precipitation under a high emissions scenario, comparing the most recent state-of-the-art climate models (CMIP6) against the previous generation of models (CMIP5). This is of critical importance since the long-term projections for the Australian monsoon have been highly uncertain in all previous generations of climate models, with little agreement on even the direction of change. The objectives of this study were twofold: firstly, to establish whether newer and presumably improved climate models have a reduced range in climate change projections for the Australian monsoon, and secondly, to determine if the range in projections are related to the same factors noted for the previous generation.

Our first key finding here is that while the range in climate change projections of Australian monsoon precipitation is reduced in CMIP6 compared to CMIP5, unfortunately the new generation of models continue to disagree on the magnitude and direction of change for the region. As was the case for CMIP5, the CMIP6 ensemble available so far have similar numbers of models that project an increase or decrease over northern Australia. To avoid the issue of climate sensitivity differences between models we have scaled the Australian monsoon precipitation changes according to each model's change in global average surface temperature. We note here, though, that models with larger global temperature changes do not necessarily have larger precipitation changes. 
To shed further light on the diversity in projected changes, we adopt the method of BR16, comparing groups of models sub-sampled based on whether they project a wetter Australian monsoon (WET) or drier Australian monsoon (DRY) in a possible future warmer climate. Here we confirm their finding using a larger ensemble (37 models instead of 33 models), that Australian monsoon projections are closely related to the western equatorial Pacific region in CMIP5 models. Repeating the analysis for the 23 available CMIP6 models we find no such relationship between Australian monsoon precipitation projections and either western equatorial Pacific SST historical climatology or future changes (Figure 3). Yet the spatial pattern of the differences in precipitation change between DRY and WET models remains similar in CMIP6 compared to CMIP5, with the DRY models having greater increases in precipitation over the western equatorial Pacific. How then can we understand the local changes in precipitation for the Australian monsoon in a warmer climate in both CMIP5 and CMIP6 models?

By comparing the meridionally-averaged tropical precipitation we find that the CMIP6 models show much smaller spread in the zonal distribution of precipitation changes than CMIP5 models (Figure 2). While the projected precipitation change in the western equatorial Pacific is larger for the DRY groups of models on average for both CMIP5 and CMIP6, it is not clear that there is a systematic relationship with Australian monsoon precipitation changes implied by the spatial composites in Figure 3. Nevertheless, the greater diversity in the zonal distribution of tropical precipitation changes in CMIP5 are consistent with differing patterns of change between models, well-documented for the CMIP5 ensemble (e.g. Chadwick et al. 2013; Grose et al. 2014b).

One of the clearest results in the present study is the link between Australian monsoon changes and the hemispheric-scale precipitation changes in both CMIP5 and CMIP6 models. Models that become drier over northern Australia also become drier in the southern hemisphere off-equatorial latitudes in general (Figures 2, 3, 4). This relationship is significantly correlated for both ensembles, although it is stronger for the CMIP6 models. We hypothesize that this may be due to the larger diversity in zonal circulation and precipitation changes contributing to northern Australian precipitation change in CMIP5 models. Indeed, the CMIP5 historical climatology differences between the DRY and WET groups show an east-west asymmetry in the Pacific basin, while the CMIP6 difference between DRY and WET groups is far more zonally symmetrical, with a slight northward location of the historical ITCZ in the DRY models (Figure 3). The spatial composites of precipitation change for DRY minus WET models show that the changes over southern hemisphere off-equatorial land regions are consistent, with the DRY models also predicting drying over southern Africa and South America. This suggests that the projected changes over the northern Australian monsoon region may not necessarily be related to western equatorial Pacific surface temperature as found by BR16 for the CMIP5 ensemble, but in fact may be more reliant on a hemispheric-scale response over land in the southern hemisphere in a future warmer climate. In other words, the reduced relationship between the western pacific SST and northern Australian precipitation changes in the newer models may have removed one source of model-to-model differences, revealing a separate hemispheric wide process. The 
processes driving the spread in models now are not clear, but one hypothesis is that feedbacks or relationships between the continental landmasses in the southern hemisphere and the location of the tropical rain bands are driving difference between these models. The analysis of these mechanisms is to be the subject of future research.

Selecting the eight models with the most extreme precipitation changes is only one approach to sub-sampling the distribution of precipitation changes. Selecting instead every second CMIP5 model at the WET and DRY tails decreases the strength of the response, but the conclusions of this study remain the same (not shown). We note however, that as more CMIP6 models become available the differences between the ensembles presented here may change.

In one sense it is perhaps good news that local or regional biases may be less important for Australian monsoon projections in the newer models, since regional fidelity in coarse global climate models is notoriously problematic (e.g. Grose et al 2014a). However, if the implications of the present study are in fact correct, then in order to improve projections of the Australian monsoon we need to better understand the hemispheric scale meridional circulation response over both ocean and land to future warming scenarios. Extending the "wet-get-wetter" theory (Held and Soden, 2006) to land regions, Byrne and O'Gorman (2015) find that horizontal gradients in warming and relative humidity changes can contribute to a drying tendency over land. Comparing the projected Australian monsoon changes to the contributions from their proposed mechanisms could be a useful step towards decreasing the projection uncertainty. However the global zonally averaged precipitation differences between the DRY and WET groups for both ensembles suggest that projections over northern Australia may hinge on the strength of an "upped-ante" response to warming, whereby in some climate models the edges of the tropical rain band dries, while the core becomes wetter (Chou and Neelin, 2004; Neelin et al, 2006). A potential avenue for future investigation could involve testing the sensitivity of precipitation changes on the southern edge of the ITCZ to modified boundary and initial conditions.

As a first attempt to explain the hemispheric scale synchronization of projected changes in precipitation, we compared the interhemispheric gradient in SST and its changes with Australian monsoon changes (Figure 4). The historical interhemispheric SST gradient was found to be weakly correlated with Australian monsoon changes for CMIP6, suggesting that the basic state in each model may be important for the future monsoon change it experiences (e.g., Zhang et al. 2018).

In conclusion, we find that changes to the Australian monsoon in a future warmer climate remain uncertain in the CMIP6 ensemble. However, one useful result of the present study is that the Australian monsoon changes are congruent with the zonal mean changes within each model. We suggest here that zonal circulation changes may be less important for the Australian monsoon in newer models, and that understanding the hemispheric-scale meridional circulation response to global warming is essential for reducing the uncertainty in Australian monsoon projections. 


\section{Acknowledgments and Data}

We acknowledge constructive comments on earlier versions of this paper by Christine Chung and Luke Osburn. The research presented in this paper was jointly supported by the Australian Bureau of Meteorology and the Australian Government's National Environmental Science Program. We acknowledge the World Climate Research Programme's Working Group on Coupled Modelling, which is responsible for CMIP, and we thank the climate modelling groups for producing and making available their model output. For CMIP, the U.S. Department of Energy's Program for Climate Model Diagnosis and Intercomparison provides coordinating support and led development of software infrastructure in partnership with the Global Organization for Earth System Science Portals. The CMIP data used in this study are freely available through the Earth System Grid Federation (https://esgf.nci.org.au/). CMAP data are freely available at https://www.esrl.noaa.gov/psd/data/gridded/data.cmap.html, and GPCP data at https://www.esrl.noaa.gov/psd/data/gridded/data.gpcp.html.

\section{References}

Adler, R.F., Huffman, G.J., Chang, A., Ferraro, R., Xie, P.P., Janowiak, J., Rudolf, B., Schneider, U., Curtis, S., Bolvin, D. and Gruber, A., 2003. The version-2 global precipitation climatology project (GPCP) monthly precipitation analysis (1979present). Journal of hydrometeorology, 4(6), pp.1147-1167.

Bellenger, H., Guilyardi, É., Leloup, J., Lengaigne, M. and Vialard, J., 2014. ENSO representation in climate models: from CMIP3 to CMIP5. Climate Dynamics, 42(7-8), pp.1999-2018.

Berry, G.J. and Reeder, M.J., 2016. The dynamics of Australian monsoon bursts. Journal of the Atmospheric Sciences, 73(1), pp.55-69.

Brown, J.R., Moise, A.F., Colman, R. and Zhang, H., 2016. Will a warmer world mean a wetter or drier Australian monsoon? Journal of Climate, 29(12), pp.4577-4596.

Byrne, M.P. and O’Gorman, P.A., 2015. The response of precipitation minus evapotranspiration to climate warming: Why the "wet-get-wetter, dry-get-drier" scaling does not hold over land. Journal of Climate, 28(20), pp.8078-8092.

Chadwick, R., Boutle, I. and Martin, G., 2013. Spatial patterns of precipitation change in CMIP5: Why the rich do not get richer in the tropics. Journal of Climate, 26(11), pp.38033822. 
Christensen, J.H., and Coauthors, 2013. Climate phenomena and their relevance for future regional climate change. Climate Change 2013: The Physical Science Basis. T. F. Stocker et al., Eds., Cambridge University Press, 1217-1308.

Chou, C. and Neelin, J.D., 2004. Mechanisms of global warming impacts on regional tropical precipitation. Journal of climate, 17(13), pp.2688-2701.

Colman, R.A., Moise, A.F. and Hanson, L.I., 2011. Tropical Australian climate and the Australian monsoon as simulated by 23 CMIP3 models. Journal of Geophysical Research: Atmospheres, 116(D10).

CSIRO and Bureau of Meteorology, 2015. Climate Change in Australia, Technical Report. Melbourne Australia. www.climatechangeinaustralia.gov.au.

Endo, H. and Kitoh, A., 2014. Thermodynamic and dynamic effects on regional monsoon rainfall changes in a warmer climate. Geophysical Research Letters, 41(5), pp.1704-1711.

Eyring, V., Bony, S., Meehl, G. A., Senior, C. A., Stevens, B., Stouffer, R. J., and Taylor, K. E.: Overview of the Coupled Model Intercomparison Project Phase 6 (CMIP6) experimental design and organization, Geoscientific Model Development, 9, 1937-1958, 2016.

Grose, M.R., Brown, J.N., Narsey, S., Brown, J.R., Murphy, B.F., Langlais, C., Gupta, A.S., Moise, A.F. and Irving, D.B., 2014a. Assessment of the CMIP5 global climate model simulations of the western tropical Pacific climate system and comparison to CMIP3. International Journal of Climatology, 34(12), pp.3382-3399.

Grose, M.R., Bhend, J., Narsey, S., Gupta, A.S. and Brown, J.R., 2014b. Can we constrain CMIP5 rainfall projections in the tropical Pacific based on surface warming patterns? Journal of Climate, 27(24), pp.9123-9138.

Held, I.M. and Soden, B.J., 2006. Robust responses of the hydrological cycle to global warming. Journal of climate, 19(21), pp.5686-5699.

Hsu, P.C., Li, T., Murakami, H. and Kitoh, A., 2013. Future change of the global monsoon revealed from 19 CMIP5 models. Journal of Geophysical Research: Atmospheres, 118(3), pp.1247-1260.

Hurley, J.V. and Boos, W.R., 2013. Interannual variability of monsoon precipitation and local subcloud equivalent potential temperature. Journal of Climate, 26(23), pp.9507-9527. 
Jourdain, N.C., Gupta, A.S., Taschetto, A.S. et al., 2013. The Indo-Australian monsoon and its relationship to ENSO and IOD in reanalysis data and the CMIP3/CMIP5 simulations. Clim Dyn 41, pp.3073-3102.

Kitoh, A., Endo, H., Krishna Kumar, K., Cavalcanti, I.F., Goswami, P. and Zhou, T., 2013. Monsoons in a changing world: a regional perspective in a global context. Journal of Geophysical Research: Atmospheres, 118(8), pp.3053-3065.

Lee, J.Y. and Wang, B., 2014. Future change of global monsoon in the CMIP5. Climate Dynamics, 42(1-2), pp.101-119.

Li, G. and Xie, S.P., 2014. Tropical biases in CMIP5 multimodel ensemble: The excessive equatorial Pacific cold tongue and double ITCZ problems. Journal of Climate, 27(4), pp.1765-1780.

Moise, A.F., Colman, R.A. and Brown, J.R., 2012. Behind uncertainties in projections of Australian tropical climate: Analysis of 19 CMIP3 models. Journal of Geophysical Research: Atmospheres, 117(D10).

Narsey, S., Reeder, M.J., Jakob, C. and Ackerley, D., 2018. An Evaluation of Northern Australian Wet Season Rainfall Bursts in CMIP5 Models. Journal of Climate, 31(19), pp.7789-7802.

Narsey, S., Reeder, M.J., Ackerley, D. and Jakob, C., 2017. A midlatitude influence on Australian monsoon bursts. Journal of Climate, 30(14), pp.5377-5393.

NCC-Editorial, 2019. The CMIP6 landscape. Nature Climate Change 9: 727-727.

Neelin, J.D., Münnich, M., Su, H., Meyerson, J.E. and Holloway, C.E., 2006. Tropical drying trends in global warming models and observations. Proceedings of the National Academy of Sciences, 103(16), pp.6110-6115.

Power, S., Casey, T., Folland, C., Colman, A. and Mehta, V., 1999. Inter-decadal modulation of the impact of ENSO on Australia. Climate Dynamics, 15(5), pp.319-324.

Risbey, J.S., Pook, M.J., McIntosh, P.C., Wheeler, M.C. and Hendon, H.H., 2009. On the remote drivers of rainfall variability in Australia. Monthly Weather Review 137: 3233-3253.

Taylor, K.E., Stouffer, R.J. and Meehl, G.A., 2012. An overview of CMIP5 and the experiment design. Bulletin of the American Meteorological Society, 93(4), pp.485-498.

Turner, A. and Annamalai, H., 2012. Climate change and the South Asian summer 
monsoon. Nature Clim Change 2, pp.587-595.

Wang, B., Liu, J., Kim, H.J., Webster, P.J. and Yim, S.Y., 2012. Recent change of the global monsoon precipitation (1979-2008). Climate Dynamics, 39(5), pp.1123-1135.

Wheeler, M.C. and McBride, J.L., 2011. Australasian monsoon. Intraseasonal Variability in the Atmosphere-Ocean Climate System, 2, pp.147-197.

Xie, P. and Arkin, P.A., 1997. Global precipitation: A 17-year monthly analysis based on gauge observations, satellite estimates, and numerical model outputs. Bulletin of the American Meteorological Society, 78(11), pp.2539-2558.

Zhang, H. and Moise, A., 2016. The Australian summer monsoon in current and future climate. In The Monsoons and Climate Change (pp. 67-120). Springer, Cham.

Zhang, H., Zhao, Y., Moise, A., Ye, H., Colman, R., Roff, G. and Zhao, M., 2018. On the influence of simulated SST warming on rainfall projections in the Indo-Pacific domain: an AGCM study. Climate dynamics, 50(3-4), pp.1373-1391. 
A

\section{CMIP5}

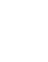

$-5$

10

언 户்

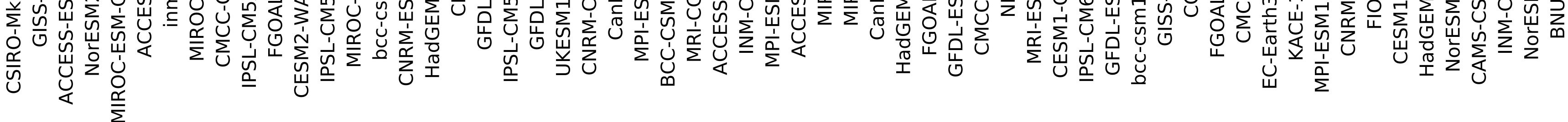

B

CMIP5

$20-$ CMIP6

$\widehat{\widehat{\pi}} \frac{\pi}{0}$ 

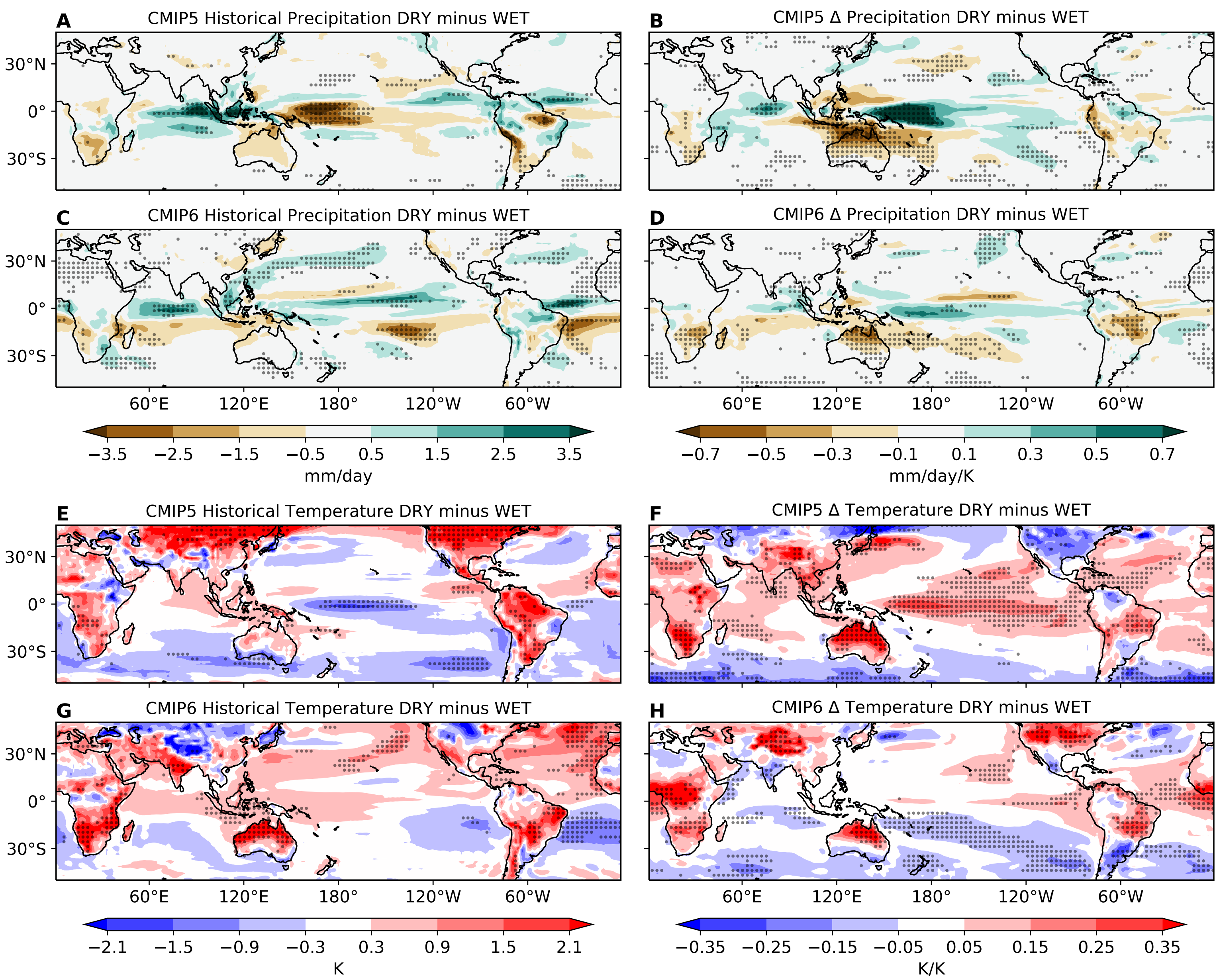


\section{University Library}

\section{- M M N E R VA A gateway to Melbourne's research publications}

Minerva Access is the Institutional Repository of The University of Melbourne

Author/s:

Narsey, SY;Brown, JR;Colman, RA;Delage, F;Power, SB;Moise, AF;Zhang, H

Title:

Climate Change Projections for the Australian Monsoon From CMIP6 Models

Date:

2020-07-16

Citation:

Narsey, S. Y., Brown, J. R., Colman, R. A., Delage, F., Power, S. B., Moise, A. F. \& Zhang, H. (2020). Climate Change Projections for the Australian Monsoon From CMIP6 Models. GEOPHYSICAL RESEARCH LETTERS, 47 (13), https://doi.org/10.1029/2019GL086816.

Persistent Link:

http://hdl.handle.net/11343/275957 